Journal of Engineering Sciences, Assiut University, Vol. 37, No. 2, pp. 281-302, March 2009.

\title{
SHEAR STRENGTH OF PLATE GIRDER WEB PANEL WITH OPENING AT ELEVATED TEMPERATURE
}

\author{
Ahmed S. Elamary \\ Lecturer, Structural Engineering Department, University of Al-Azhar, Qena-Egypt
}

(Received February 17, 2009 Accepted March 16, 2009)

\begin{abstract}
For flexibility of accommodating building service plants, openings are often introduced to the web of steel beams which affects the structural behaviour of the beams. The available design methods developed only for the ambient temperature situation. This paper is concerning with the effect of web opening in the ultimate shear capacity of the web panel at elevated temperature. The investigation will include the plate girders web panel containing centrally circular or square holes. In order to provide accurate assessment to the shear load carrying capacity of plate girder web panel with openings, a finite element model was established with both material and geometrical non-linearity by using ANSYS software package. Accuracy of the model is assessed by applying it to plate girders tested earlier by other researchers. Comparison of analytical results with the available experimental results for yielding patterns, ultimate load values and load-deflection relationships show good agreement between the finite element and experimental results thus validating the accuracy of the proposed model. A parametric study is undertaken to gain additional insight into the overall behaviour, failure modes, and deformation capacity for circular and square shapes of web panel openings with various sizes at elevated temperature. From these analyses, it is concluded that, variation of the ultimate shear capacity of plate girders with respect to the size of openings for girders with circular or square openings dropped continuously with increasing the temperature and the size of opening; and the drop in load carrying capacity increases significantly as the temperature increase and the opening size gets larger in size. Finally, an equation based on the results of numerical finite element analyses proposed to anticipate the reduction of the ultimate shear force due to circular or square opening size.
\end{abstract}

KEYWORDS: shear load, plate girder, web opening, elevated temperature.

\section{INTRODUCTION}

In modern buildings, openings are frequently required to be provided in structural members so that building services may be incorporated into structural zones for simplified layout and installation. Moreover, the overall depth of the construction zone may be reduced accordingly, and it may become beneficial for multi-storey buildings with large headroom requirement. At present, there is a tendency to use in the plumbing system and in the air conditioning system of increasing sizes, and openings 
of dimensions up to $70 \%$ of the depth of floor beams are often required as shown in Fig $1-a$ and $b$. The presence of web openings may have a severe penalty on the load carrying capacities of floor beams, depending on the shapes, the sizes, and the locations of the openings. Both Square and circular openings are commonly used, and reinforcements around the web openings may be provided as necessary through rational design.

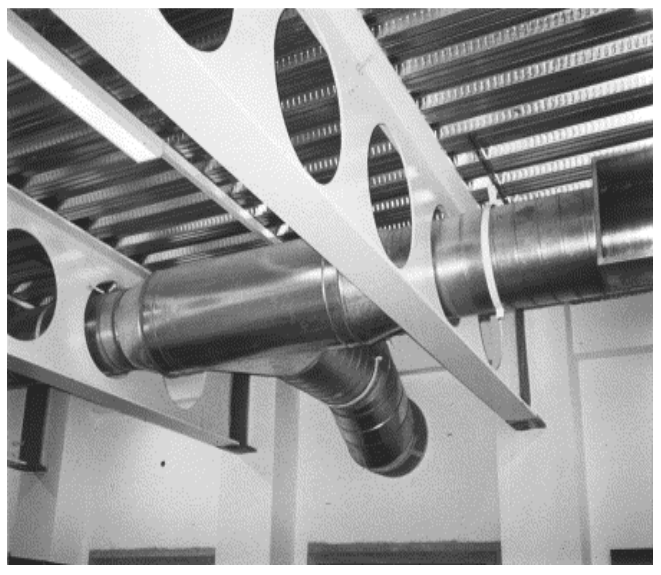

a. Circular opening for air conditioning Sys.

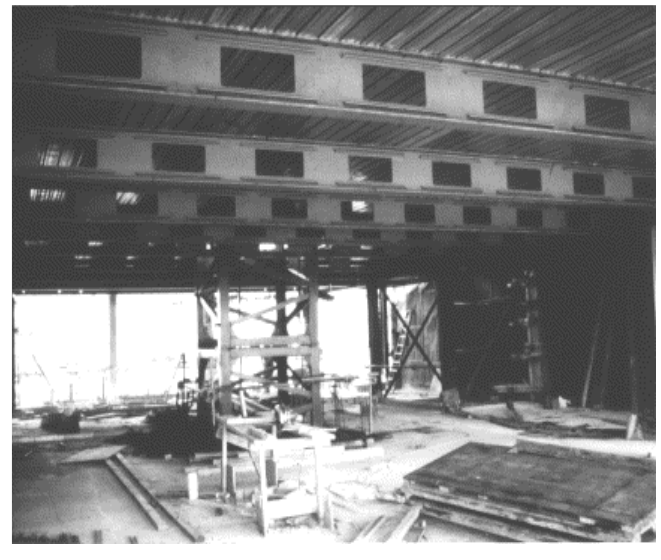

b. Rectangular opening for building facilities.

Fig.1 Circular and rectangular web openings

Castellated beams with both hexagonal and circular web openings are also commonly used where web openings are provided along the beams at regular intervals for flexible routing and re-routing of building services. The presence of web openings in steel beams introduces three different modes of failure at the perforated sections: (1) Shear failure due to reduced shear capacity, (2) Flexural failure due to reduced moment capacity, (3) 'Vierendeel' mechanism, due to the formation of four plastic hinges in the tee-sections above and below the web openings under the Vierendeel action, i.e. transferring of lateral shear force across a web opening.

At elevated temperature studying beams with openings in the web should be distinguished by whether or not they are axially restrained. For an axially unrestrained beam with web openings, when designing for elevated temperatures in fire, it is acceptable to use the limiting temperature concept to assess the beam performance. The limiting temperature is the temperature of the beam at which the bending moment resistance of the beam is reduced to the bending moment caused by the externally applied load in the fire situation (which is similar to the applied load at the serviceability limit state). The beam may be considered to be safe if the beam temperature in fire does not exceed the limiting temperature. However, for a beam that is axially restrained, using the limiting temperature (which is based on bending moment resistance) may not be suitable because the beam may fail either before or after the beam has reached its limiting temperature. This is because axial restraint may force the beam into catenary action (in which the beam is in tension) $[7,18]$. 


\section{LITERATURE REVIEW AND THEORETICAL BACKGROUND}

\subsection{Steel beams with web openings of common shapes}

A large amount of research efforts on the structural behavior of steel beams with web openings have been reported in the literature over the last three decades, and most of the research work on perforated sections may be classified into the following two types of construction:

1. Hot-rolled steel beams with single web openings: For universal steel beams, rectangular web openings were often formed with aspect ratios ranging from 1.03.0 while the opening depth, $\mathrm{d}_{\mathrm{o}}$, was commonly restricted to about $50 \%$ of the overall section height, $\mathrm{h}$. Welded steel plates might be provided above and below the web openings to reinforce the perforated sections. Circular web openings were also popular in commercial buildings with high specifications in building services due to easy installation of water pipes.

2. Fabricated beams with multiple web openings: Castellated steel beams were fabricated from universal beams with profile cutting and welding so that the overall beam depth was increased by $50 \%$ for enhanced structural performance against bending. In typical construction, the opening depth, $d_{o}$, is $2 / 3$ of the overall section height of the castellated section while the length of the tee-sections above and below the opening is only a quarter of the opening depth roughly, producing a very efficient perforated section against Viereendel mechanism. In these types of beams, no reinforcements are normally provided.

\section{3-2. Strength of Plate Girder Web Panel Loaded in Shear under Ambient Condition}

For a plate girder subjected to a small shear load, bending theory can be used to determine how the internal forces are carried by the web and the flanges. When the applied load is increased, the failure mode of a plate girder will depend largely on the panel aspect ratio $(b / d)$ and the web slenderness ratio $(d / t)$, where $b$ is the clear distance between vertical stiffeners, and $d$ and $t$ are the clear depth and the thickness of the web panel, respectively. When the panel is stocky, the web will fail by yielding in shear, which is governed by the theoretical shear yield strength $\tau_{y w}=\sigma_{y w} / \sqrt{3}$, where $\sigma_{y w}$ is the

uniaxial tensile yield strength of the web. For most practical plate girders, however, web panels are generally thin and tend to buckle first before yielding. The overall behaviour of a web panel is thus divided into three stages, (1) unbuckled, (2) postbuckled, and (3) collapsed stage.

\subsubsection{Unbuckled Stage}

If a uniform shear stress is applied to the web, there will be a principal tensile stress of magnitude $\tau$ acting throughout the whole web. This stress state will continue until the applied shear stress reaches the critical shear strength $\tau_{c r}$ which can be determined from classical stability theory for plates by Timoshenko and Gere [15]:

$\tau_{c r}=K\left[\frac{\pi^{2} E}{12\left(1-\mu^{2}\right)}\right]\left(\frac{t}{d}\right)^{2} \leq \tau_{y w}$ 
The buckling coefficient $K$ is obtained from the following equation

$$
\begin{aligned}
& K=5.35+4\left(\frac{d}{b}\right)^{2}, \text { for } \frac{b}{d}>1 \\
& K=5.35\left(\frac{d}{b}\right)^{2}+4, \text { for } \frac{b}{d}<1
\end{aligned}
$$

Where: $E$ the modulus of elasticity, and $\mu$ is the Poisson's ratio.

Therefore, the shear load that causes the web plate to buckle is given by:

$V_{c r}=\tau_{c r} d t$.

Although the notion of real boundary condition at the juncture between web and flanges to be somewhere between simply supported and fixed has been recognized from early days. Recent studies show that the restraint provided by the flanges could enhance the buckling coefficient $K$, which would lead to an enhancement in shear strength [17]. In this paper the boundary condition has been arbitrarily and conservatively assumed to be fixed.

\subsubsection{Post-Buckled Stage}

Once the critical shear strength is reached, the web cannot carry any increase in shear load. Additional shear force will be supported by the mobilization of tensile membrane stress $\sigma_{t}$ in the diagonal band of the web. For a web panel subjected to pure shear, the value of $\sigma_{t}$ that causes the web to yield can be written as

$$
\sigma_{t y}=-\frac{3}{2} \tau_{c r} \sin 2 \theta+\sqrt{\sigma_{y w}^{2}+\tau_{c r}^{2}\left[\left(\frac{3}{2} \sin 2 \theta\right)^{2}-3\right]}
$$

where the angle $\theta$ is the inclination of the membrane tensile yielding strength $\sigma_{t y}$. It should be mentioned that, the above equation is applied only if $\tau_{c r}$ less than or equal $\tau_{y w}$.

\subsubsection{Collapsed Stage}

Failure of the plate girder occurs when sufficient numbers of hinges have formed in the top and bottom flanges; together with the diagonal yield zone, the web panel forms a plastic sway mechanism. The additional shear load $V_{f}$ sustained by the web panel until it collapses is determined from a consideration of virtual work applied to the sway mechanism [19]:

$$
\begin{aligned}
& V_{f}=2 c t \sigma_{t y} \sin ^{2} \theta+\sigma_{t y} d t \sin ^{2} \theta\left(\cot \theta-\cot \theta_{d}\right) \\
& c=\frac{2}{\sin \theta} \sqrt{\frac{M_{P f}}{\sigma_{t y} t}}
\end{aligned}
$$

The first term on the right hand side of Eq. (5) represents the contribution of flanges to panel shear strength. The value of $c$ is obtained by considering the equilibrium of the panel between the two plastic hinges in the flange, and $\theta_{\mathrm{d}}$ is governed by the panel aspect ratio $\left(\cot \theta_{\mathrm{d}}=d / b\right)$.

$V_{u l t}=V_{c r}+V_{f}$ 
In the above equations the ultimate shear load $V_{u l t}$ and the inclination of principal tensile stress $\theta$ are unknown. A parametric study for the ambient case shows that the variation of $V_{u l t}$ with $\theta$ is not abrupt [19]. It was suggested that the assumption of $\theta=2 \theta_{\mathrm{d}} / 3$, in order to maximize $V_{u l t}$ where $\cot \theta_{\mathrm{d}}=d / b$ [9]. The BS 5950: Part 1 [1], provided a simplified version of the shear strength equations based on the assumption that $\theta=\theta_{\mathrm{d}} / 2$ which is used in this paper. The above calculation method based on Cardiff method which is not applicable for unstiffened girders and for high web aspect ratios; since these procedures leads to $V_{u l t} \rightarrow 0$ [9].The Cardiff method preferred than Basler's method because it is more suitable for the reliability level, which has to be achieved with the needed uniformity; as recommended by M. Sulyok et al. [9].

\subsection{Panels under the Combination of Shear and Compression}

Eurocode 3 Part 1.1 [4] stated that, for ambient condition, if the applied shear force is less than $50 \%$ of the shear buckling resistance, there is no interaction between shear and compression; otherwise, the interaction has to be considered. In extending the pure shear case for a panel including axial stress, previous work assumed that the flanges are subjected to additional axial forces, while the stress system in the web remains the same as under pure shear $[19,20]$.

At the buckling stage, the elastic buckling of simply supported thin plate can be predicted by an approximate interaction between the two stress ratios. Thus, for panels subjected to shear and uniform compression at ambient condition as shown in Fig. 2(a), the following formula suggested by Horne can be adopted [19].

$\frac{\sigma_{c}}{\sigma_{x c r}}+\left(\frac{\tau}{\tau_{c r}}\right)^{2}=1$

where $\sigma_{c}$ and $\tau$ are the applied compressive and shear stresses, respectively, $\sigma_{x c r}$ is the critical-buckling stress for the plate when it is subjected to a pure compression given by

$\sigma_{x c r}=K_{c}\left[\frac{\pi^{2} E}{12\left(1-\mu^{2}\right)}\right]\left(\frac{t}{d}\right)^{2} \leq \sigma_{y w}$

which $K_{c}$ is the buckling coefficient, obtained as

$K_{c}=\frac{m^{2}}{(b / d)^{2}}+\frac{(b / d)^{2}}{m^{2}}+2$

where $m$ is a number of sinusoidal half-waves in the direction of compression force. It is well known that for a simply supported flat plate having the aspect ratio $b / d \geq 1, K_{c}$ approaches 4 . Thus, for a panel under a compressive stress $\sigma_{c}$, the reduced buckling shear stress denoted by $\tau_{c r}^{\prime}$ can be calculated from Eq. (11) as:

$\tau_{c r}^{\prime}=\tau_{c r}\left(1-\frac{\sigma_{c}}{\sigma_{x c r}}\right)^{1 / 2}$ 


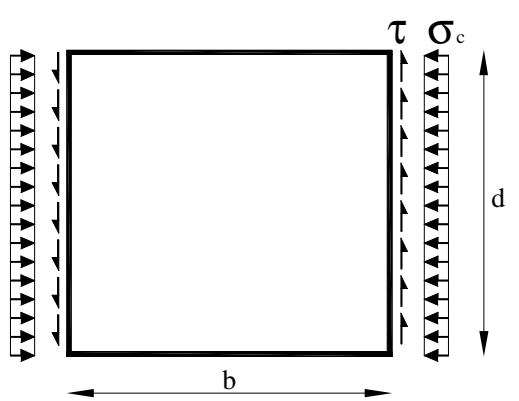

(a) Panel subject to combined shear and compression

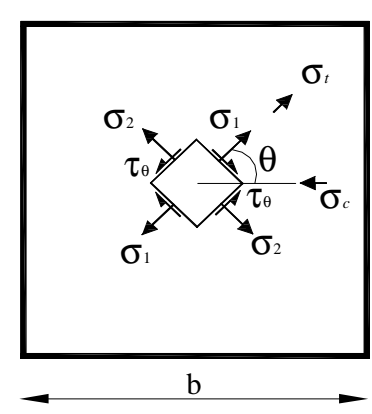

(b) Stress components of an element in the panel

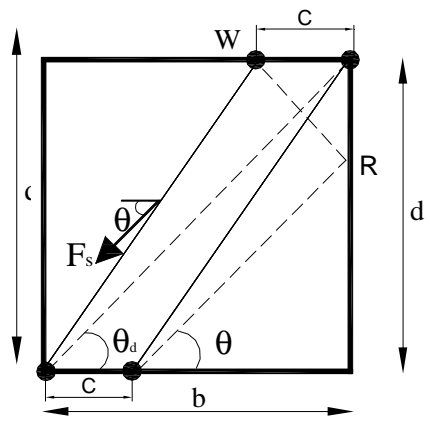

(c) System of forces acting in the post-buckled range.

Fig. 2. Web panel behavior under combined shear and compression.

After buckling, the panel behavior is expected to undergo the post-buckled and collapsed stages, as in the pure shear case. The stress components developed in the post-buckling stage include the compressive stress $\sigma_{c}$, the shear stress $\tau$, and the tensile stress developed in the diagonal band of the panel $\sigma_{t}$, as shown in Fig. 2.(b). The element stresses on the inclined plane at $\theta$ and $90^{\circ}+\theta$ to the tensile flange are given by Eqs. (12), (13), and (14). Substituting these equations into the Von Mises yield equation for the web Eq.(15), the value of $\sigma_{t y}^{\prime}$ which results in the yielding of web is given in Eq. (16).

$\sigma_{1}=-\frac{\sigma_{c}}{2}-\frac{\sigma_{c}}{2} \cos 2 \theta+\tau_{c r}^{\prime} \sin 2 \theta+\sigma_{t}$

$\sigma_{2}=-\frac{\sigma_{c}}{2}+\frac{\sigma_{c}}{2} \cos 2 \theta-\tau_{c r}^{\prime} \sin 2 \theta$

$\tau_{\theta}=\frac{\sigma_{c}}{2} \sin \theta+\tau_{c r}^{\prime} \cos 2 \theta$

$\sigma_{1}^{2}+\sigma_{2}^{2}-\sigma_{1} \sigma_{2}+3 \tau_{\theta}=\sigma_{y w}^{2}$

$\sigma_{t y}^{\prime}=A_{1}+B_{1}+C_{1}$

$A_{1}=-\frac{3}{2} \tau_{c r}^{\prime} \sin 2 \theta$

$B_{1}=\sqrt{\sigma_{y w}^{2}+\tau_{c r}^{\prime 2}\left[\left(\frac{3}{2} \sin 2 \theta\right)^{2}-3\right]+\tau_{c r}^{\prime} \sigma_{c} D_{c}}$

$C_{1}=\frac{\sigma_{c}}{4}(3 \cos 2 \theta+1)$

$D_{c}=\frac{1}{4}(3 \cos 2 \theta+1)(3 \sin 2 \theta)+\frac{1}{16}(3 \cos 2 \theta+5)(3 \cos 2 \theta-3) \frac{\sigma_{c}}{\tau_{c r}^{\prime}}$ 
Under the presence of axial stress $\sigma_{c}$ in the flanges, the reduced plastic moment of resistance of the compression and tension flanges that attain the yield strength $\sigma_{y f}$ is given by Eq.(21). The location of the plastic hinges is given by Eq.(22)

$$
\begin{aligned}
& M_{P f}^{\prime}=M_{P f}\left[1-\left(\frac{\sigma_{c}}{\sigma_{y f}}\right)^{2}\right] \\
& c=\frac{2}{\sin \theta} \sqrt{\frac{M_{P f}^{\prime}}{\sigma_{t y} t}}
\end{aligned}
$$

From the equilibrium of internal and external forces in the post-buckled stage, as shown in Fig. 2-(c), the vertical component of membrane tensile field must be equal to the external shear force

$V_{u l t}=F_{s} \sin \theta+V_{c r}^{\prime}$

where, from web equilibrium,

$$
\begin{aligned}
& V_{c r}^{\prime}=\tau_{c r}^{\prime} d t \\
& F_{S}=\sigma_{t y}^{\prime} t[2 c \sin \theta+(d \cot \theta-b) \sin \theta]
\end{aligned}
$$

The term $F_{s}$ is the resultant of web membrane stresses across $W R$, as marked in Fig. 2(c).

\subsection{Strength of Plate Girder Web Panel at Elevated Temperature}

Under elevated temperature conditions, the material properties deteriorate as temperature rises. For steel material, the temperature-dependent yield strength $\sigma_{y(T)}$ and the elastic modulus $E_{(T)}$ at temperature $T$ can be expressed as a fraction of their ambient values, which are denoted by subscript (20) in the following linear form:

$$
\begin{aligned}
& \sigma_{y(T)}=K_{y(T)} \sigma_{y(20)} \\
& E_{(T)}=K_{E(T)} E_{(20)}
\end{aligned}
$$

Where subscript $(T)$ denotes the value corresponding to elevated temperature; $K_{y(T)}$ and $K_{E(T)}$ are the retention ratios of the material yield strength and elastic modulus, respectively. Eqs. (1), (2), (3), (4), (5), (6) and (7) extended to consider the panel shear strength under the effects of elevated temperature by Ting et al. [19].

In should be noted that in the numerical and the analytical predictions in this paper, the strength of the steel at elevated temperature was taken by considering the strength retention ratio at $0.5 \%$ strain as recommended by Eurocode 3 Part 1.2 [5]. The strength at $0.5 \%$ strain is also recommended in BSI (2003) for the design analysis of an element that is susceptible to buckling.

\section{3-5 Steel Beams with Perforated Sections}

The presence of web openings may have a severe penalty on the load carrying capacities of structural members, depending on the configurations of the web openings. In general, both the shear and the moment capacities of the perforated sections may be 
readily assessed. However, the moment capacities of the tee-sections above and below the web openings under local moments are relatively difficult to be evaluated in the presence of co-existing axial and shear forces due to global bending action. Moreover, it is necessary to use plastic design to incorporate the formation of four plastic hinges in the tee-sections for an improved prediction of the load carrying capacity of the beams. Liu et al. [7]; concluded that all the primary structural characteristics of steel beams with perforated sections are similar to each other for the difference in shapes and sizes of web openings. In a perforated section under a global moment $\mathbf{M}_{\mathrm{g}}$ and a global shear force $\mathrm{V}_{\mathrm{g}}$ three local actions are induced in the tee-sections above and below the web opening as shown in Fig. 3:

- Axial force in the tee-section, $\mathrm{N}_{\mathrm{T}}$, due to the global moment $\mathrm{M}_{\mathrm{g}}$.

- Shear force in the tee-section, $\mathrm{V}_{\mathrm{T}}$, due to the global shear force, $\mathrm{V}_{\mathrm{g}}$.

- Local moment in the tee-section, $\mathrm{M}_{\mathrm{T}}$, due to the transfer of shear force $\mathrm{V}_{\mathrm{g}}$ across the opening length.
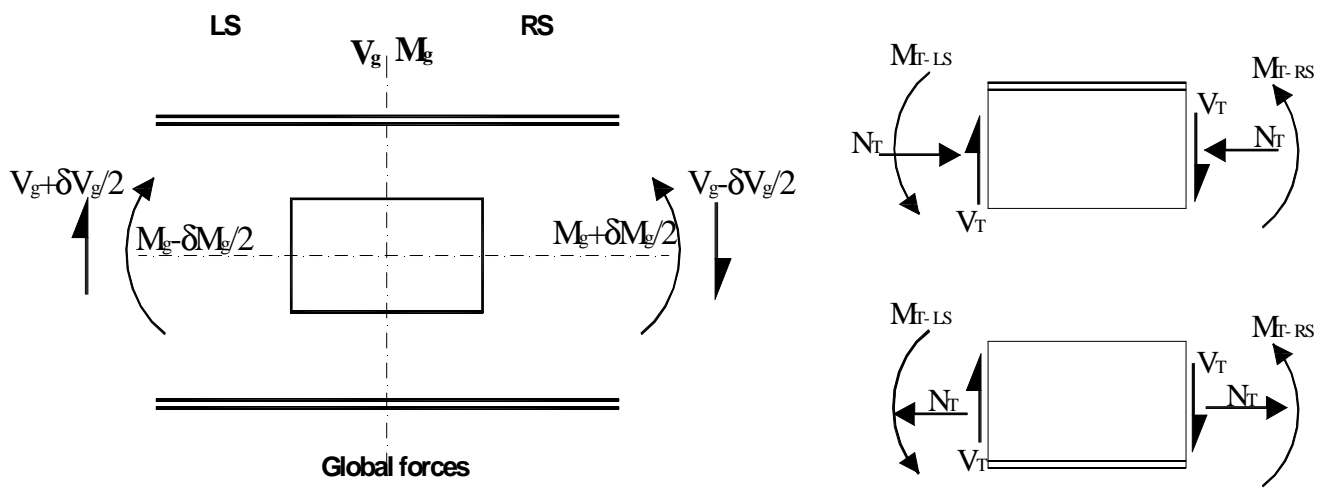

Fig. 3. Force distribution in a perforated section

For beams with given loading and support conditions, the magnitudes of these local actions depend on the shapes, the sizes, and also the locations of the openings. Beams with multiple web openings, buckling of web posts may be critical when the openings are closely spaced. Moreover, additional deflection due to the presence of web openings should also be considered. Failure mechanism which can be performed in this case called Vierendeel mechanism. This mechanism is always critical specially in steel beams with single large web openings, where global shear force is transferred across the opening length, and the Vierendeel moment is resisted by the local moment resistances of the tee-sections above and below the web openings [7]. At present, most of the current design methods recommend empirical interaction formulae on the moment resistances of the tee-sections to allow for the presence of local axial and shear forces. They ignore the true ultimate behaviour of the tee-sections under co-existing axial and shear forces and bending moment [7]. Consequently, it should be mentioned that, this paper will by concern only with the single and central web opening.

\section{THEORETICAL ANALYSIS:}

Using visual basic program, an EXCEL spreadsheet including all the above mentioned equations, executed as an analytical tool for quantifying the ultimate shear load. By 
using this programmed sheet the ultimate shear in both ambient and elevated temperature can be calculated for shear web panel without opening. The input data required by this program are the geometric and material properties of both web and flanges and the temperature value need to obtain the ultimate shear on it. The program is able to determine the ultimate shear force for the web panel with a range of temperatures between $20^{\circ}$ to $1200^{\circ}$. This study focused in additional to the ambient temperature, five others elevated temperature levels; which were $400^{\circ}, 500^{\circ}, 600^{\circ}$, $700^{\circ}$, and $800^{\circ} \mathrm{C}$. These values of temperature represented the range where steel material properties vary the most.

Based on these values of temperature the created EXCEL spreadsheet calibrated by calculating the ultimate shear values related to different values of temperature on a series of plate girder web panel previously studied and published by other researches. Table 1 reported the geometric and material properties of three plate girder web plane studied previously by V. Vimonsatit et al.[19, 20]; which were the calibration tools for the theoretical program.

Table 1. Geometric and material properties of G1-G3 series

\begin{tabular}{|c|c|c|c|c|c|c|c|c|c|}
\hline \multirow{2}{*}{ Panel } & \multicolumn{7}{|c|}{ Geometric properties } & \multicolumn{2}{|c|}{$\begin{array}{l}\text { Material Properties at } \\
\qquad \mathbf{2 0}^{\circ} \mathrm{C}\end{array}$} \\
\hline & $\begin{array}{c}t \\
(\mathbf{m m})\end{array}$ & $\underset{(\mathbf{m m})}{b}$ & $\underset{(\mathbf{m m})}{d}$ & $\begin{array}{c}b_{f} \\
(\mathbf{m m})\end{array}$ & $\begin{array}{c}\boldsymbol{t}_{f} \\
(\mathbf{m m})\end{array}$ & $d / t$ & $b / d$ & $\begin{array}{c}\sigma_{y w} \\
\left(\mathbf{N} / \mathbf{m m}^{2}\right)\end{array}$ & $\sigma_{y f}\left(\mathrm{~N} / \mathrm{mm}^{2}\right)$ \\
\hline (1) & (2) & (3) & (4) & (5) & (6) & (7) & $(8)$ & (9) & (10) \\
\hline G1 & 0.965 & 304.8 & 304.8 & 76.2 & 5 & 315.9 & 1 & 224 & 289 \\
\hline G2 & 2 & 305 & 305 & 80 & 6 & 152.5 & 1 & 248 & 275 \\
\hline G3 & 1.22 & 305 & 305 & 80 & 6 & 250 & 1 & 248 & 275 \\
\hline
\end{tabular}

The results of this comparison reported in table.2; columns 3, 5, and 7. The comparison shows that the ultimate shear forces were agreed to a very good degree of accuracy.

\section{FINITE ELEMENT ANALYSIS}

\section{5-1 General}

During the past twenty years, the use of finite element model to study non-linear behaviours of structural members has spread to many fields of engineering. Different finite element software packages have been adopted for modelling structural members by other researchers. Narayanan and Der Avanessian [14] proposed a simplified finite element formulation to study tension field developed in the post critical stages, when a plate girder with web openings is subjected to predominant shear loading. A modified Von Mises criterion was used to simplify the computational process.

To gain further insight into the behavior of plate girder web panel with opening and under shear load at elevated temperature, a finite element model of the tested web 
panel plate girder conducted by Ting [19] was developed. Fig 5.b shows the mesh of the developed FE model. In this study, the commercial finite element package ANSYS [2] was used. The four nodes shell elements SHELL43 available in ANSYS were adopted for the discretization of both the web and the flanges of the panel section. The material properties of steel were specified using the elastic and the metal plasticity with plastic options. The model dimensions and properties were directly adopted from the measured values of experimental specimens. Newton's iterative technique was used to analyse the non-linear response of the model under loading. The analysis process was controlled by material yielding which was defined by the von Mises, yield and shear stress functions. Further details of formulation and computations in the analysis can be found from ANSYS manuals [2].

\section{5-2 Comparison with Experimental and Numerical Results}

There are two aspects in predicting the fire resistance of structural components. The first one, is by evaluating the strength at elevated temperature and where, the second by evaluating the maximum temperature that the structural component can sustain under a constant applied load. The author calibrated the capability of ANSYS finite element models applying both aspects in two different published experimental and analytical papers as will be reported later herein.

\subsubsection{Comparison with Test Results of Liu et al. [18]}

The author previously calibrated the capability of ANSYS to deal with the steel beams, subjected bending moment and fire, by comparing the performed finite element model with the test results on restrained steel beams at large deflections performed by Liu et al. [18]. Fig.4-a, and b show the results of different level of loading ratio 0.5 and 0.7 applied in this test. It can be seen that the simulation results are in good agreement with the test results. More and full details of these comparison and test process can be found in the author publication [1].

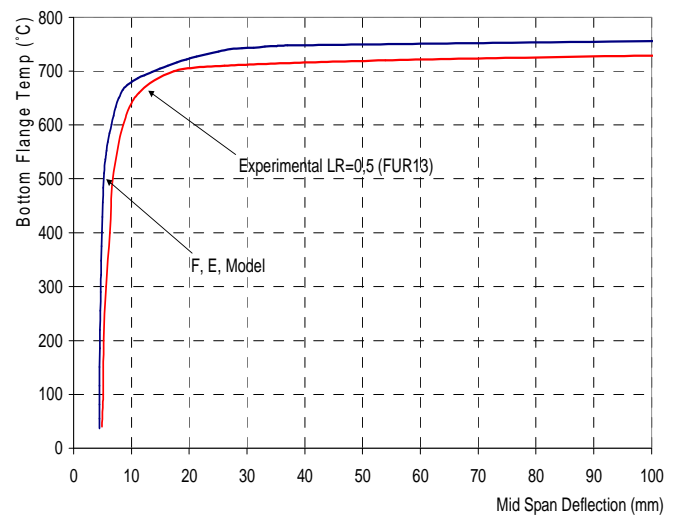

(a) Comparison at $50 \%$ ultimate load resistance

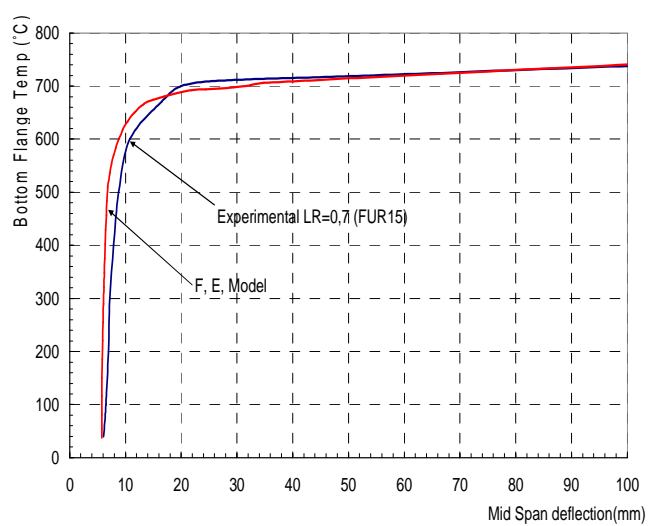

(b) Comparison at $70 \%$ ultimate load resistance

Fig.4 Comparison between experimental and F.E. Model subjected to bending and fire 


\subsubsection{Comparison with Test Results of V.Vimonsatit et al. $[19,20]$}

In order to calibrate the model under shear load, the same ANSYS shell elements with the same material assumption and analysis process mentioned above were used in the following verifications process too. In this case, the boundary conditions at the edges of the panel model simulated the transverse stiffeners that remained straight throughout heating and the loading processes. This assumption was consistent with the theoretical analysis $[19,20]$. The boundary conditions of the FE model for the local translations, $x$, $\mathrm{y}$, and $\mathrm{z}$, and the rotations, $\theta_{\mathrm{x}}, \theta_{\mathrm{y}}$, and $\theta_{\mathrm{z}}$, respectively shown in the brackets in Fig. 5.a; where 1 represents fixed, and 0 free. Full model at the end of the analysis with buckled web shown in Fig.5.b. The plastic hinges deformation and the stress generated in the web panel at the end of the analysis shown in Fig.5 c. and d respectively.
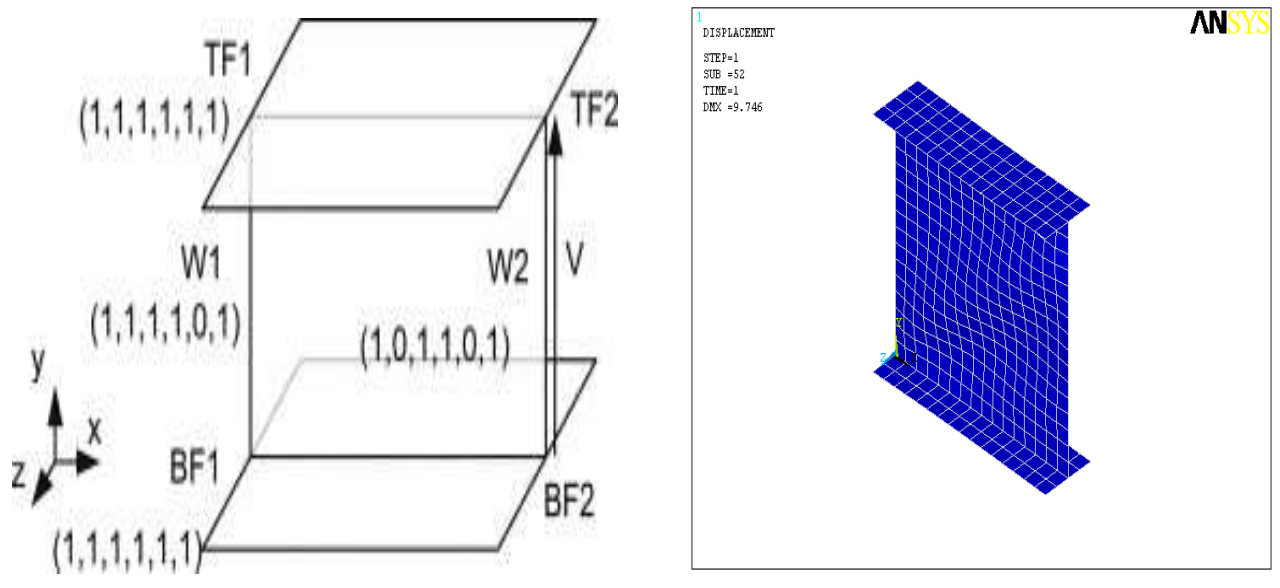

a- F.E. Model Boundary conditions [19]

b- Web buckling at failure

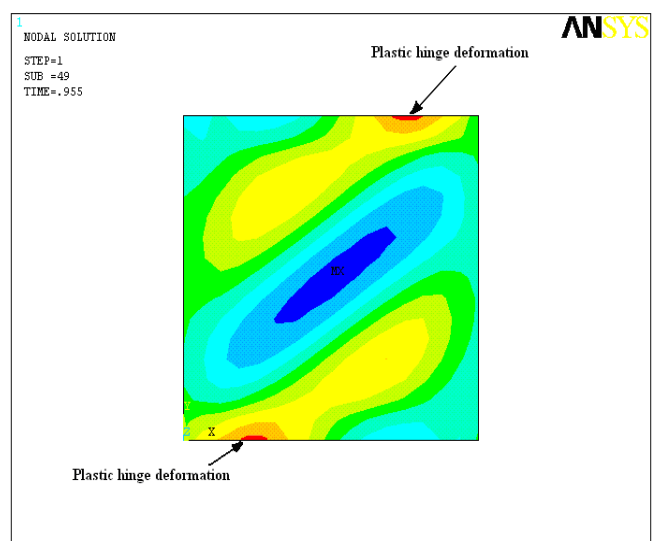

c- Plastic hinge deformation

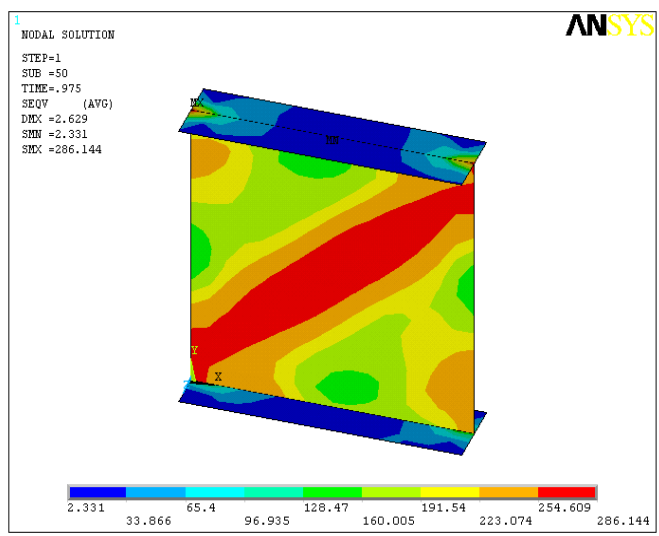

d- Web panel at failure

Fig.5 Finite element model for web panel under shear

The results obtained from the series of shear web panels with the geometric and material properties shown in table 1 , are reported in table 2 ; columns 4,6 , and 8 . 
Two different comparisons where conducted, the first was with the previous analytical and experimental study performed by V. Vimonsatit et al. [19, 20], where the second was with the theoretical values resulted from the EXCEL program mentioned previously and shown in column (5) in table 2 . From this comparison it can noticed that, the finite element method seems to overestimate the load-carrying capacity in a few cases whilst in some cases it underestimates. The comparison shows that the finite element modelling is able to predict the failure load with sufficient accuracy in most cases the error does not exceed $10 \%$.

Table 2:- Comparisons between Numerical and Analytical verification obtained by EXCEL and F.E.M results for G1-G3 series under ambient and elevated temperatures

\begin{tabular}{|c|c|c|c|c|c|c|c|}
\hline \multirow[b]{2}{*}{ Panel } & \multirow[b]{2}{*}{$\begin{array}{l}\text { Temp } \\
\left({ }^{\circ} \mathrm{C}\right)\end{array}$} & \multicolumn{2}{|c|}{$\begin{array}{l}\text { Values presented by V. } \\
\text { Vimonsatit et al. [19] }\end{array}$} & \multicolumn{2}{|c|}{ Present study } & \multicolumn{2}{|c|}{ Percentage of differences } \\
\hline & & $\begin{array}{l}V_{u l t}(\mathbf{k N}) \\
\text { theoretical }\end{array}$ & $V_{F E M}(\mathbf{k N})$ & $\begin{array}{l}V_{u l t}(\mathbf{k N}) \\
\text { theoretical }\end{array}$ & $V_{F E M}(\mathbf{k N})$ & $\begin{array}{l}V_{u l t} / V_{u l t} \\
\text { (Theoretical) }\end{array}$ & $\begin{array}{l}V_{F E M} / V \\
\text { (Modell } \\
\text { eing) }\end{array}$ \\
\hline (1) & (2) & (3) & (4) & (5) & (6) & $(3) /(5)=(7)$ & $\begin{array}{c}(4) /(6)= \\
(8)\end{array}$ \\
\hline \multirow{4}{*}{ G1 } & Ambient & 28.8 & 28.1 & 28 & 27.8 & 1.03 & 1.01 \\
\hline & $400^{\circ}$ & 22.05 & 21.9 & 21.8 & 21.5 & 1.01 & 1.02 \\
\hline & $550^{\circ}$ & 13.45 & 13 & 12.95 & 12.8 & 1.04 & 1.02 \\
\hline & $700^{\circ}$ & 4.74 & 4.4 & 4.7 & 4.5 & 1.01 & 0.98 \\
\hline \multirow{4}{*}{ G2 } & Ambient & 77.52 & 78.2 & 77.5 & 78 & 1.00 & 1.00 \\
\hline & $400^{\circ}$ & 58.35 & 56.6 & 56.91 & 55.6 & 1.03 & 1.02 \\
\hline & $550^{\circ}$ & 35.75 & 35.2 & 35.7 & 35.5 & 1.00 & 0.99 \\
\hline & $700^{\circ}$ & 12.36 & 12.4 & 12.3 & 12.5 & 1.00 & 0.99 \\
\hline \multirow{4}{*}{ G3 } & Ambient & 42.96 & 40.1 & 40.9 & 40.7 & 1.05 & 0.99 \\
\hline & $400^{\circ}$ & 32.88 & 31.7 & 31 & 33 & 1.06 & 0.96 \\
\hline & $550^{\circ}$ & 20.05 & 18.9 & 19.4 & 19 & 1.03 & 0.99 \\
\hline & $700^{\circ}$ & 7.07 & 6.8 & 6.75 & 7 & 1.05 & 0.97 \\
\hline
\end{tabular}




\section{6- EFFECT OF CIRCULAR WEB OPENINGS}

For steel beams with circular web openings, most of the design rules are applicable using an equivalent rectangular opening of modified dimensions, as suggested by Redwood [13]. However, due to the simplistic approach, the load carrying capacities of steel beams are always underestimated significantly. Elastic stress distribution in beams with large circular web openings have been examined by Chan and Redwood [12] using the theory of elasticity and the curved beam analysis. In order to assess the load carrying capacities of steel beams with multiple circular web openings in an explicit manner, a design method based on the research works of Olander [10] and Sahmel [11] was developed at the Steel Construction Institute in 1990. The method was later incorporated into Amendment A2 of Eurocode 3 [4]: Part 1.1: Annex N, in 1998 after minor modification. However, for steel beams with individual circular web openings, the use of a different set of approximate design rules was recommended in Annex N.

In this investigation, the analysis executed for a web panel with dimension $500 \times 500 \mathrm{~mm}$. The web depth and flange width were fixed at $500 \mathrm{~mm}$ and $100 \mathrm{~mm}$, respectively. The ratio of the flange thickness to the web thickness, $t_{f} / t$, was set equal to 2.0. The web and flange thicknesses were fixed at $5 \mathrm{~mm}$ and $10 \mathrm{~mm}$, respectively. Material properties were: modulus of elasticity, $E=205 \mathrm{Gpa}$; specified minimum yield stress, $F_{y}=360 \mathrm{MPa}$; and Poisson's ratio, $\mu=0.3$. The shear loading was applied as shown in Fig. 6-a, and $\mathrm{b}$ as a pure shear state. The analysis started by determined the ultimate shear which could be achieved by the web panel without opening. The circular opening size performed on the center of the web panel and the analysis performed for six different sizes of $\beta$ ranged from a diameter equal $20 \%$ to $70 \%$ of web height with $10 \%$ increment. Fig. 5-a, and b show the model for web panel with $200 \mathrm{~mm}$ diameter ( $\beta=40 \%$ \{Open height/web height $\}$ ) and $300 \mathrm{~mm}$ diameter $(\beta=60 \%)$ respectively.

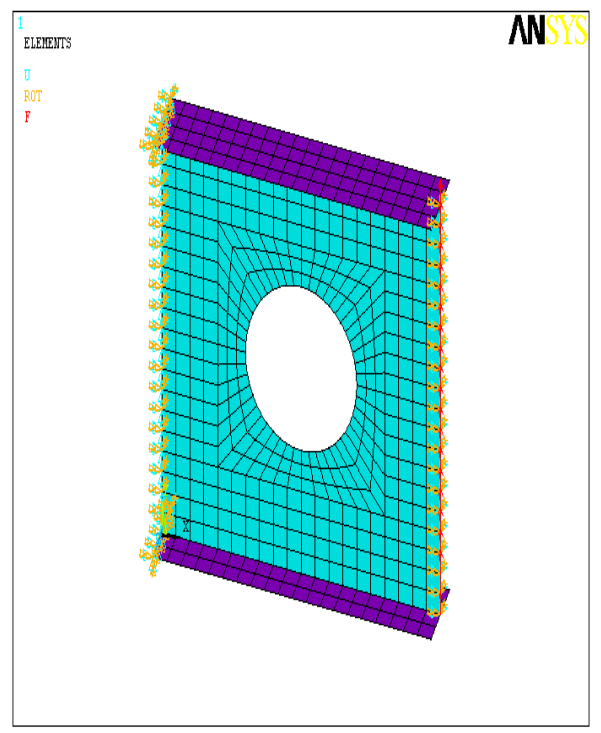

a. Web panel with circular opening $\beta=40 \%$

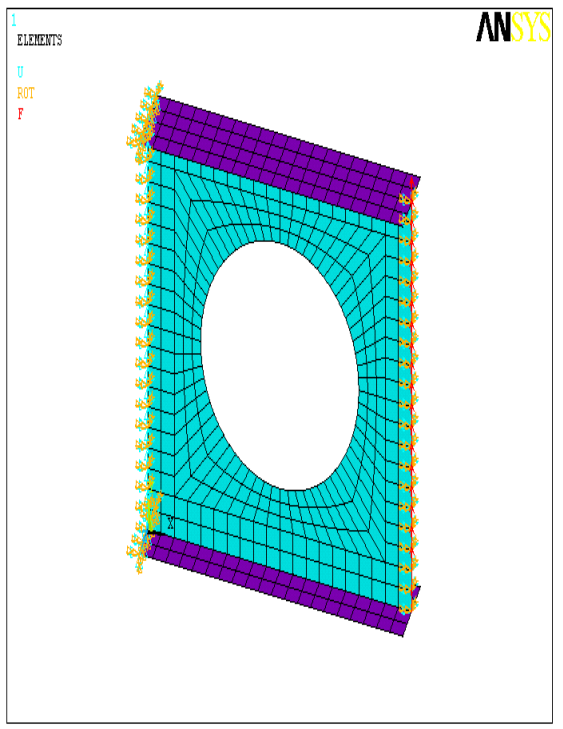

b. Web panel with circular opening $\beta=60 \%$

Fig.6 Finite element model of plate girder web panel with circular opening. 
In the FE analyses at ambient and elevated temperatures the shear load $\mathrm{V}$ was applied gradually until the panel failed to sustain a further load increment. In these analyses, the applied shear load was uniformly distributed along the web edge marked W2 in Fig. 5(a).

The analysis results showing that, at yield stress value 'Vierendeel' mechanism, was performed due to the formation of four plastic hinges in the teesections above and below the web openings as show in Fig.7-a. Under the Vierendeel action, the lateral shear force across a web opening was transferring. By continue to increase the shear force applied at edge W2 the diagonal stress increased significantly up to failure as shown in Fig.7-b. The maximum shear stress at failure is shown in Fig.7-c. In this figure it is shown that the maximum shear strength zones located mainly above and under the opening and close to the interaction line between the web and the flanges. At the end, the obtained shape of the buckled shear web panel at failure shown in Fig.7-d.
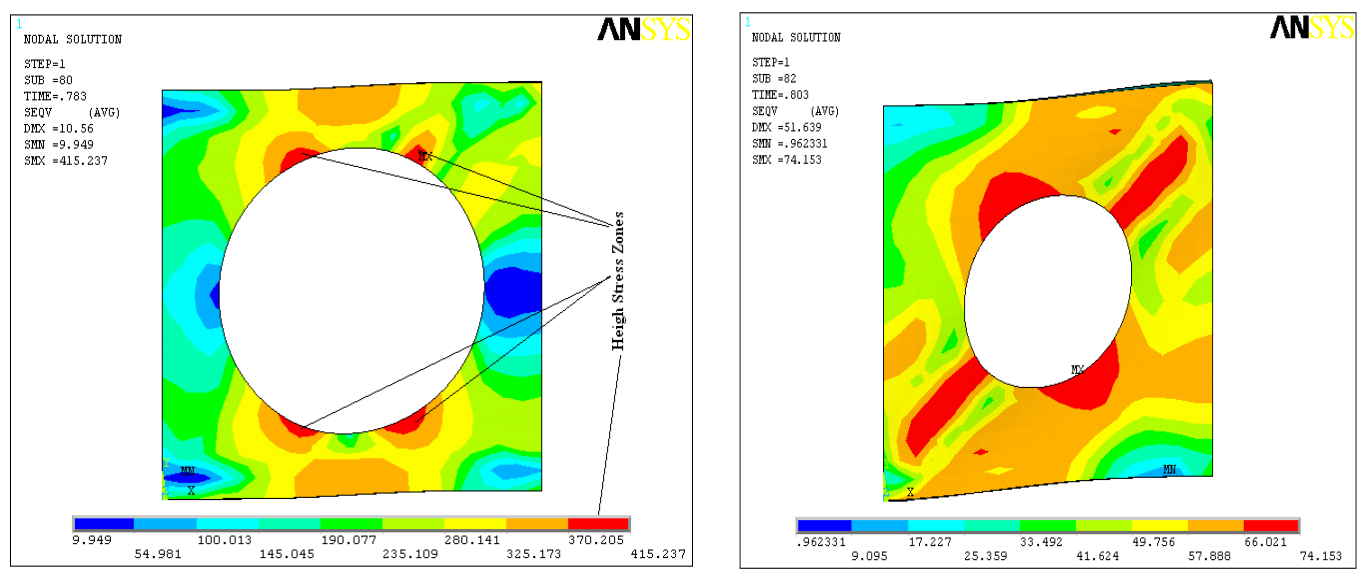

a. Von Mises stress at ambient temp. $-\beta=70 \%$

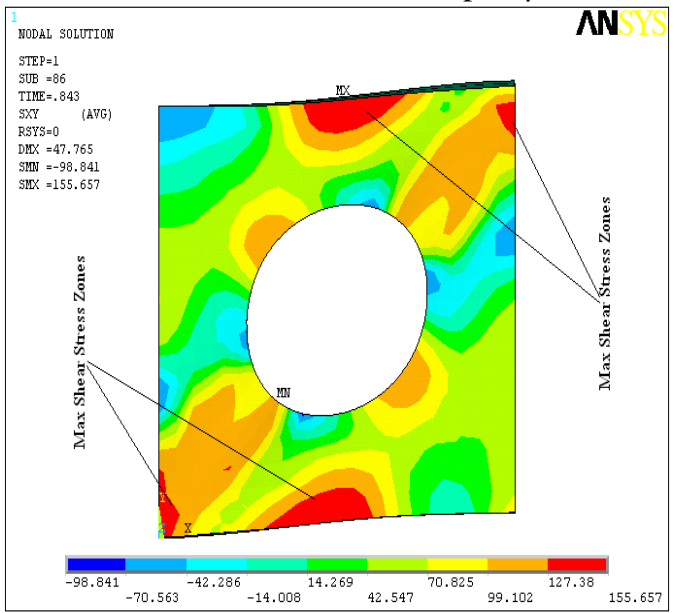

b. Von Mises stress at failure $\mathrm{C}=700^{\circ}-\beta=50 \%$

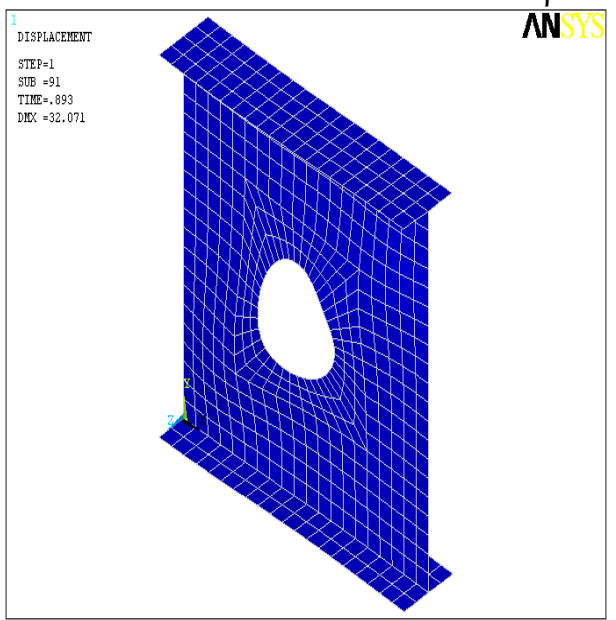

c. Shear stress of web panel at $400^{\circ}-\beta=50 \%$

d. Buckling of web at $500^{\circ}-\beta=30 \%$

Fig.7 Von-Mises and shear stress at failure 


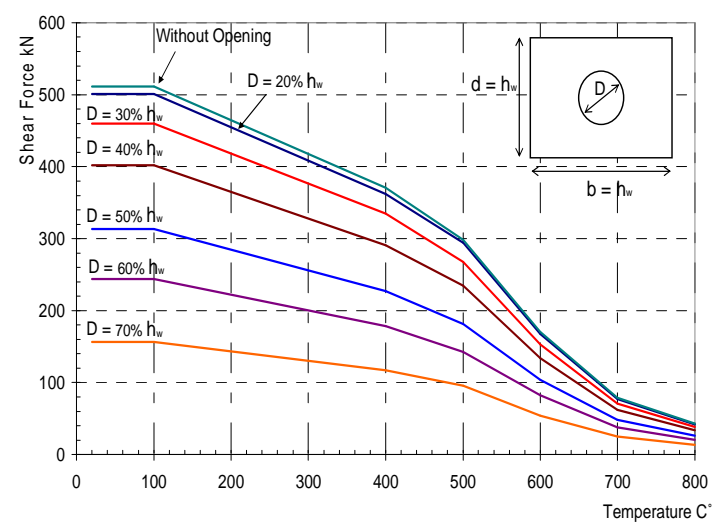

a- Shear Force vs. Temperatures

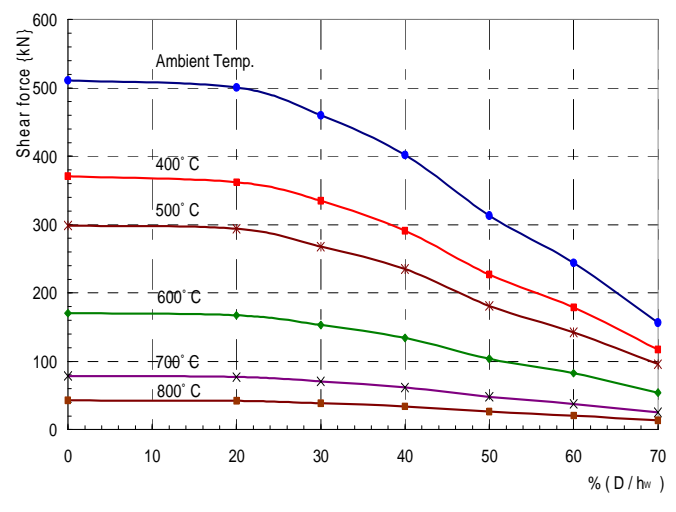

b- Shear force vs. ( $\beta$ ) (Open/web height)

Fig.8 Maximum Shear forces of web plane with circular opening

Variation of the ultimate shear capacity of plate girders with respect to the temperature and the size of openings for girders with circular openings are shown in Fig. 8-a. The figure shows that the failure load dropped continuously with increasing size of opening and the drop in load carrying capacity increases significantly as the opening size gets larger in size. After the temperature reached $600^{\circ}$ the effect of web opening size start to be decreased till $800^{\circ}$ the effect can be ignored.

Table 3:- Maximum shear force obtained analytically by FE Model (Circular openings)

\begin{tabular}{|c|r|r|r|r|r|r|r|}
\hline \multirow{2}{*}{$\begin{array}{c}\text { Temperature } \\
\mathbf{C}^{\circ}\end{array}$} & \multicolumn{6}{|c|}{ Maximum shear force resulted from F. E. Model (kN) } \\
\cline { 2 - 8 } & $\boldsymbol{\beta}=0 \%$ & $\boldsymbol{\beta}=20 \%$ & $\boldsymbol{\beta}=30 \%$ & $\boldsymbol{\beta}=40 \%$ & $\boldsymbol{\beta}=50 \%$ & $\boldsymbol{\beta}=60 \%$ & $\boldsymbol{\beta}=70 \%$ \\
\hline $20^{\circ}$ & 511.28 & 495.56 & 435.65 & 318.25 & 240.80 & 156.56 & 132.00 \\
\hline $400^{\circ}$ & 370.65 & 360.25 & 315.64 & 229.58 & 172.60 & 116.48 & 94.80 \\
\hline $500^{\circ}$ & 298.50 & 288.65 & 254.65 & 185.46 & 140.08 & 93.50 & 78.75 \\
\hline $600^{\circ}$ & 170.45 & 165.36 & 145.68 & 106.50 & 80.80 & 53.40 & 43.50 \\
\hline $700^{\circ}$ & 78.67 & 76.59 & 67.10 & 48.60 & 36.74 & 24.25 & 20.10 \\
\hline $800^{\circ}$ & 42.85 & 41.70 & 36.56 & 26.57 & 20.31 & 13.12 & 11.02 \\
\hline
\end{tabular}

From table.3 and Fig.8-b, it can be noticed that where the percentage of diameter of the performed opening to the web height equal $20 \%, 30 \%, 40 \%, 50 \%$, $60 \%$, and $70 \%$ the reduction of the ultimate shear force are $2 \%, 10 \%, 21 \%, 39 \%, 52 \%$, and $69 \%$ respectively. These percentages of reduction are almost constant at each level of temperature independently.

Liu et al. [7], concluded that, for all web openings of various shapes and sizes considered in their investigation, the most important parameter in assessing the structural behaviour of the perforated sections was the critical opening length. This length of the web opening was controlled the magnitude of the local Vierendeel moments acting on the tee-sections. While the opening depth controlled the shear and the moment resistances of the perforated section, Moreover, it was stated that, all other geometrical parameters of the web openings did not affect the structural behaviour of the perforated sections at all. Furthermore, all the steel beams with web openings of various shapes and sizes which studied by Liu et al. [7] behave similarly among each other in terms of deformed shapes under a wide range of applied moments and shear 
forces. Consequently, the main factor which could affect the web panel with open was the opening dimensions.

Since the reduction percentage in ultimate stresses is mainly based on the size and the shape of the opening; Eq. (27) is a new formula proposed to anticipate the reduction value in the ultimate shear force which could be obtained due to the size of this opening respect to web height.

$$
R_{V}=\frac{\left(C_{1}^{0}+C_{2}^{0} \beta+C_{3}^{0} \beta^{2}\right)}{\left(1+C_{4}^{0} \beta+C_{5}^{0} \beta^{2}+C_{6}^{0} \beta^{3}\right)}
$$

Where,

$R_{V}$ Reduction factor of the maximum shear force for the web panel without opening $\beta=($ Open diameter $/$ Web height $) * 100$

The six $\mathrm{C}$ constants can be taken as follow:
$C_{1}^{0}=-$
$C_{2}^{0}=$
$C_{3}^{0}=$
$C_{4}^{0}=$ -
$C_{5}^{0}=$
$C_{6}^{0}=-$
1.04E-4,
$1.46 \mathrm{E}-4$,
$1.59 \mathrm{E}-5$,
0.04652 ,
0.00081 ,
$4.62 \mathrm{E}-6$

The formula calibrated by applying different values of $\beta$ started from 5\% to $75 \%$; the obtained relevant reduction values are indicated by solid circular points in Fig. 9. Where, the results obtained from the finite element model plotted as a curve in the same figure. From this figure it can be noticed that the formula can anticipate the reduction of the maximum shear forces with high accuracy.

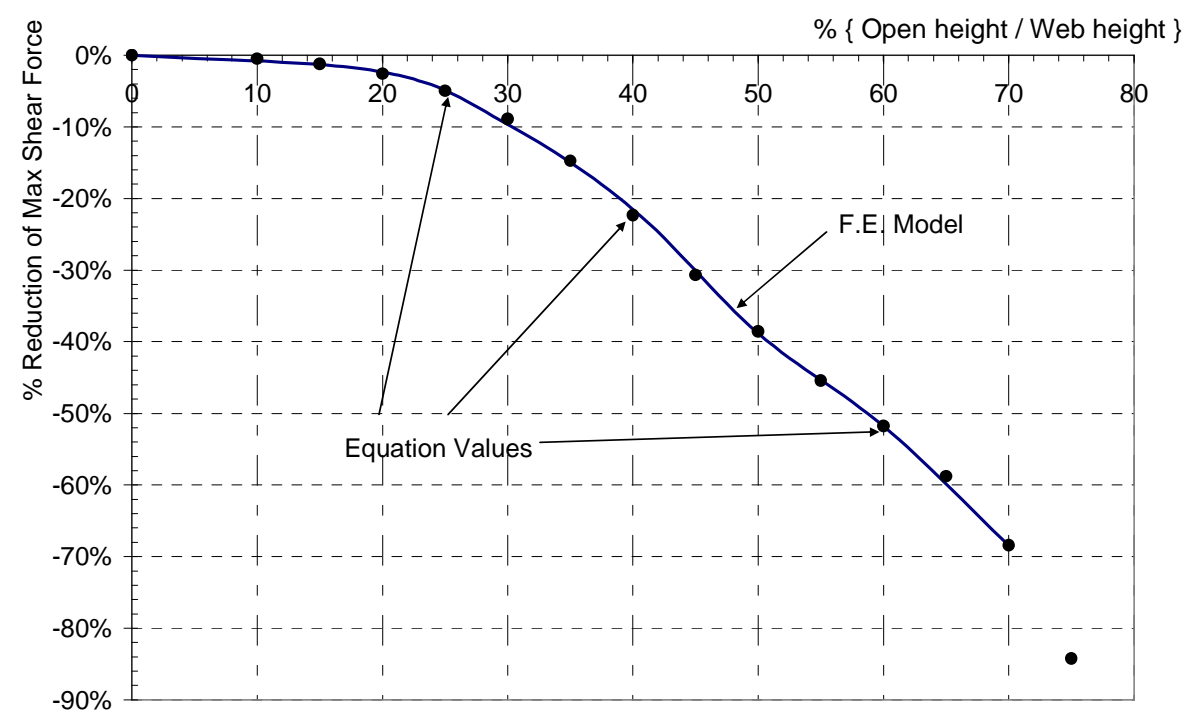

Fig.9 Comparison between proposed formula and FE Model.

\section{7- EFFECT OF SQUARE WEB OPENINGS}

In this analysis the web panel has the same dimensions and material properties of the flanges and web mentioned above for circular openings. The analysis procedures also started by determined the ultimate shear which can be achieved by the web panel without opening. The square opening size performed on the center of the web panel and the analysis performed for six different sizes started with a width equal $20 \%$ to 
$70 \%$ of web height with $10 \%$ increment. Fig. 10-a, and b show the model for web panel with $150 \mathrm{~mm}$ width (30\% of web height) and $250 \mathrm{~mm}$ width (50\% of web height) respectively.

In the FE analyses at ambient and elevated temperatures the shear load $\mathrm{V}$ was applied gradually until the panel failed to sustain a further load increment. In these analyses, the applied shear load was uniformly distributed along the web edge marked W2 in Fig. 5(a).

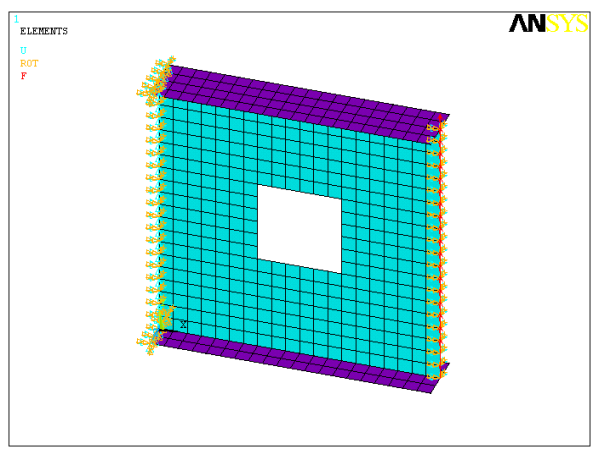

a. Web panel with square opening ( $\beta=30 \%$ )

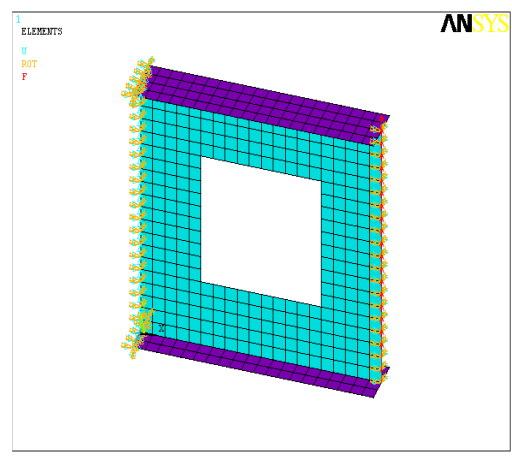

b. Web panel with square opening $(\beta=50 \%)$

Fig.10 Finite element model of plate girder web panel with square opening

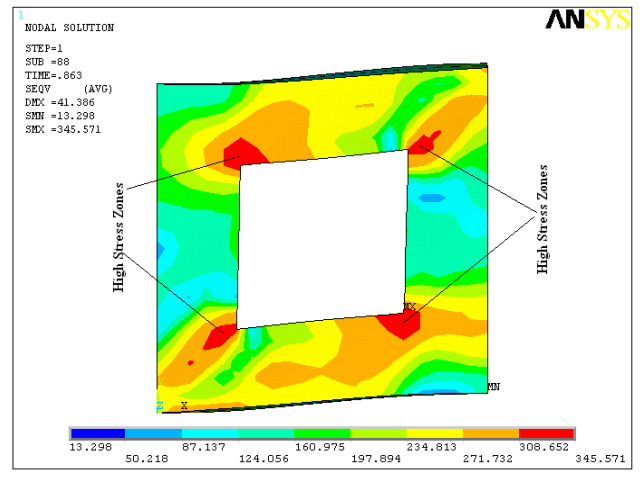

a. Von Mises stress at $400^{\circ}-\beta=50 \%$

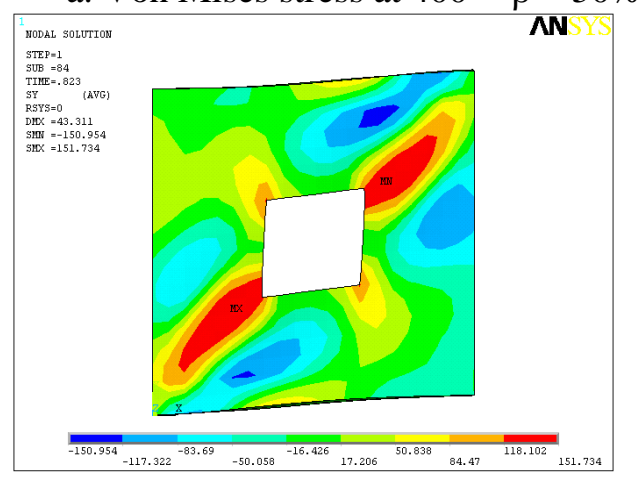

c. Stress in $\mathrm{Y}$ direction at $600^{\circ}-\beta=30 \%$

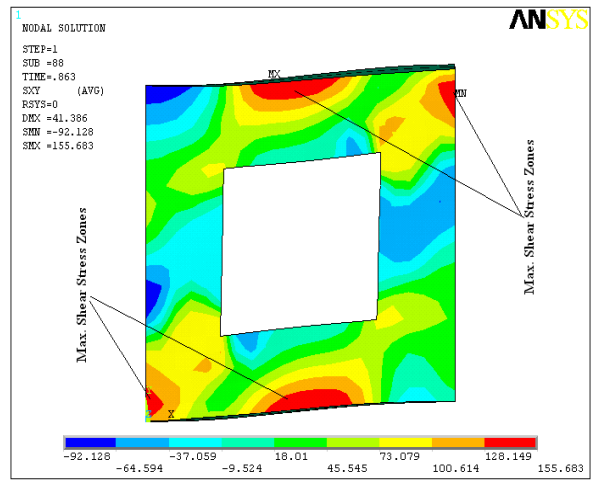

b. Shear stress at $400^{\circ}-\beta=50 \%$

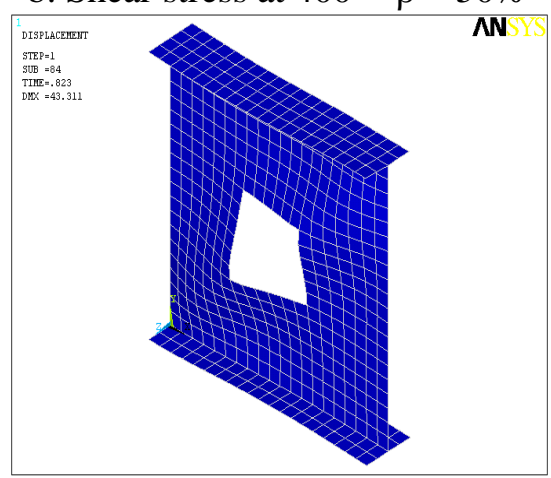

d. Web buckling at $600^{\circ} \mathrm{C}-\beta=30 \%$

Fig.11 Von Mises and shear stress at failure 
The analysis results showing that, at yield stress value 'Vierendeel' mechanism, was performed due to the formation of four plastic hinges in the teesections at the four corners above and below the web openings as show in Fig.11-a. By continue to increase the shear force applied at edge W2 the shear stress increased significantly up to failure as shown in Fig.11-b. In this figure it is shown that the maximum shear strength zones which were located mainly above and under the opening close to the interaction line between the web and the flanges similar to previously obtained in the circular opening. On the other hand, the vertical stress distribution across the web mainly concentrated in nearest top corner and far lower corner from the load side as shown in Fig.11-c. Those two zones were the buckled areas in the shear web panel as shown in Fig.11-d.

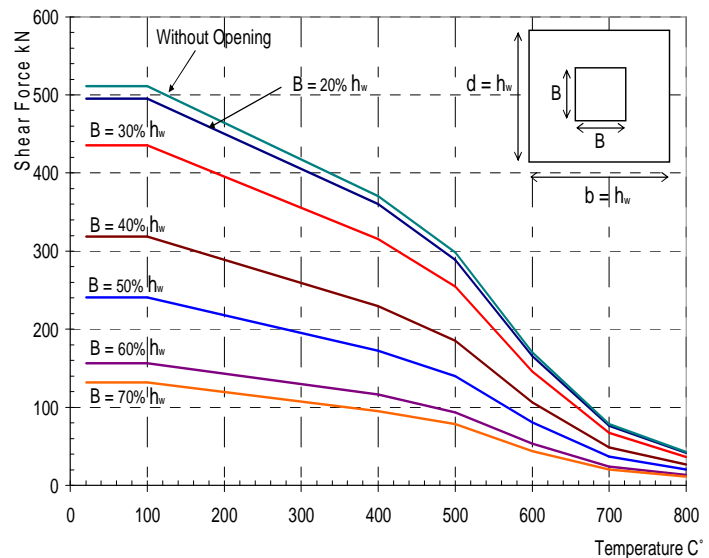

a- Shear Force vs. Temperatures

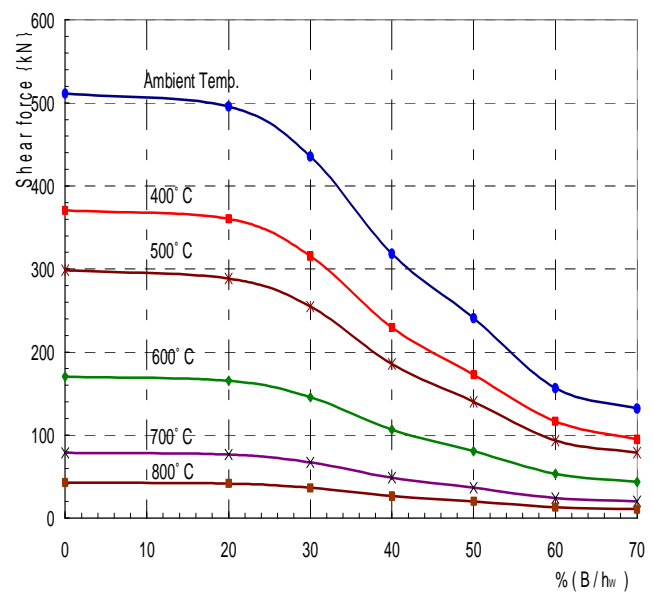

b- Shear force vs. ( $\beta$ ) (Open/web height)

Fig.12 Maximum Shear forces of web plane with square opening

From table.4 and Fig.12, it can be noticed that, in case of the percentage of width of opening to the web height equal $20 \%, 30 \%, 40 \%, 50 \%, 60 \%$, and $70 \%$ the reduction of the ultimate shear force are $3 \%, 15 \%, 38 \%, 53 \%, 69 \%$, and $74 \%$ respectively. These percentages of reduction are almost constant at each level of temperature independently. The same notices regarding to the relation between the shear capacity and the temperature and web opening stated above for circular opening can be drawn herein for the square opening.

Table 4:- Maximum shear force obtained analytically by FE Model (Square openings)

\begin{tabular}{|c|r|r|r|r|r|r|r|}
\hline \multirow{2}{*}{$\begin{array}{c}\text { Temperature } \\
\mathbf{C}^{\circ}\end{array}$} & \multicolumn{6}{|c|}{ Maximum shear force resulted from F. E. Model (kN) } \\
\cline { 2 - 8 } & $\boldsymbol{\beta}=0 \%$ & $\boldsymbol{\beta}=20 \%$ & $\boldsymbol{\beta}=30 \%$ & $\boldsymbol{\beta}=40 \%$ & $\boldsymbol{\beta}=50 \%$ & $\boldsymbol{\beta}=60 \%$ & $\boldsymbol{\beta}=70 \%$ \\
\hline $20^{\circ}$ & 511.28 & 495.56 & 435.65 & 318.25 & 240.80 & 156.56 & 132.00 \\
\hline $400^{\circ}$ & 370.65 & 360.25 & 315.64 & 229.58 & 172.60 & 116.48 & 94.80 \\
\hline $500^{\circ}$ & 298.50 & 288.65 & 254.65 & 185.46 & 140.08 & 93.50 & 78.75 \\
\hline $600^{\circ}$ & 170.45 & 165.36 & 145.68 & 106.50 & 80.80 & 53.40 & 43.50 \\
\hline $700^{\circ}$ & 78.67 & 76.59 & 67.10 & 48.60 & 36.74 & 24.25 & 20.10 \\
\hline $800^{\circ}$ & 42.85 & 41.70 & 36.56 & 26.57 & 20.31 & 13.12 & 11.02 \\
\hline
\end{tabular}


Equation 27 stated above, applied to anticipate the reduction factor for plate girder web panel with square opening; where $\beta=$ (Open height / Web height $) * 100$; and the six $\mathrm{C}$ constants in this shape of opening can be taken as follow:

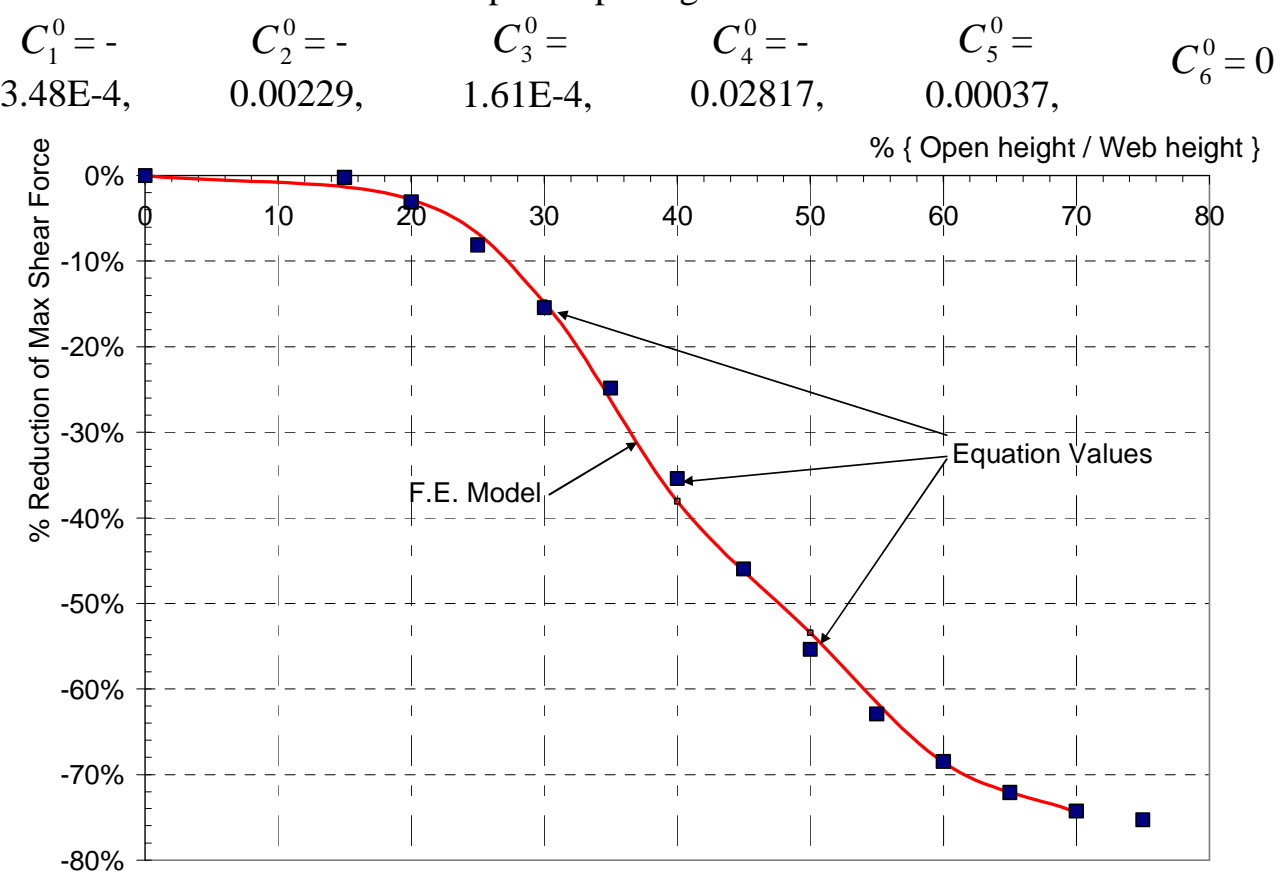

Fig.13 Comparison between proposed formula and F. E. Model.

By applying the six constant shown above in Eq. (27) the reduction values in the ultimate shear force in web panel with single and central square opening obtained for various values of $\beta$ started from 5\% to 75\%. The obtained values from equation are indicated by solid square points in Fig. 13, where the results obtained from the finite element model plotted as a curve in the same figure. From this figure it can be noticed that the formula can anticipate the reduction of the maximum shear forces with less but acceptable accuracy than obtained in the circular opening case.

\section{CONCLUSIONS}

The purpose of this investigation was to ascertain the ultimate shear strength effect of steel beams with perforated sections at elevated temperature. Finite element analyses of web panel plate girder with central and singular circular or square openings presented in this paper. The non-linear behaviour and ultimate shear capacity of web panel plate girders, tested earlier by other researchers, simulated by using three dimensional finite element models executed by ANSYS software package. The model was capable of simulating the behaviour of the web panel and provided very good results. At elevated temperatures, the critical shear strength, the tensile yield stress at the post buckled stage, and the ultimate shear strength at the collapse stage derived by taking into account the degraded material properties, with assumption of uniform temperature distribution across and along the web panel and flanges. Through this analysis, the 
overall behaviour of the plate girder under shear was studied by applying a uniform shear force acting throughout the whole web height. Due to this force the web panel shear stress state continued until reached the critical shear strength $\tau_{\mathrm{cr}}$. Once the critical shear strength was reached, additional shear force supported by the mobilization of tensile membrane stress $\sigma_{t}$ in the diagonal band of the web until yield. The failure of the plate girder started to be occurred after the plastic hinges had formed (Vierendeel mechanism). The main conclusions from this studied can be summarized as follow:-

- Variation of the ultimate shear capacity of plate girders with respect to the temperature and the size of openings for girders with circular or square openings dropped continuously with increasing the temperature and the size of opening; and the drop in load carrying capacity increases significantly as the opening size gets larger in size.

- The ultimate shear of web panel can be affected significantly by the size of the web opening where the temperature is less than $600^{\circ}$. After the temperature reached $600^{\circ}$ the effect of web opening size start to be decreased till $800^{\circ}$; after that level of temperature the effect of web opening size can be minor.

- The width of membrane stresses developed along a diagonal band, which carry the applied load in the post-critical stage, is reduced by the largest dimension of the hole

- Based on the results obtained from the numerical finite element analyses, an equation proposed to anticipate the reduction of the ultimate shear force which can be resisted by the shear web panel due to circular or square opening size. This equation can be used at each level of temperature.

- Tee-sections above and below the web openings may thus be accurately evaluated in the presence of co-existing axial and shear forces. Moreover, load redistribution across the web openings after yielding may be incorporated with full strength mobilization of the perforated sections against Vierendeel mechanism.

- The position of the maximum shear stress mainly concentrated in zones close to the flange and in the central length of the tee sections above and below the web opening.

- Due to the web opening the positions of the plastic hinges completely changed from area close to web-flange junction to the four corners of the opening.

- The corners of square openings should be curved in order to minimize or to eliminate stress concentration.

- The response of plate girders with slender web containing openings depends strongly on the dimension of the opening. A number of analyses should be conducted to investigate the sensitivity of the structure to imperfections.

\section{REFERENCES:}

1. A. Elamary "Nonlinear behavior analysis of steel beams with flat or corrugated webs at elevated temperatures" Journal of engineering sciences, Assiut University, May, 2008.

2. ANSYS User's Manual, Version 9, 2004 
3. BS 5950: Part 1. Structural Use of Steelwork in Building. Code of Practice for Design-Rolled and Welded Sections. British Standards Institution; 2000.

4. ENV 1993-1-3, Eurocode 3: Design of steel structures: Part 1.1. General rules and rules for buildings, 1992, and Amendment A2 of Eurocode 3: Annex N 'Openings in webs'. British Standards Institution, 1998.

5. Eurocode 3. Part 1.2. Design of steel structures: Part 1.2 General Rules. Structural Fire Design, EN 1993-1-2:2005. Brussels (Belgium): Commission of European Communities; 2005.

6. J.K. Ward. Design of composite and non-composite cellular beams, The Steel Construction Institute (1990).

7. K. F. Chung, T. C. H. Liu "Steel beams with large web openings of various shapes and sizes: finite element investigation" Journal of constructional steel research Volume 59 (2003) pp. 1159-1176

8. M.A. Bradford, Improved shear strength of webs designed in accordance with the LRFD specification, Engineering Journal 33 (3) (1996), pp. 95-100.

9. M. Sulyok, T.V. Galambos "Evaluation of web buckling test results on welded beams and plate girders subjected to shear" J Engineering Structures June 1996, pp. 459-464.

10. Olander HC. A method of calculating stress in rigid frame corners. J Struct Div Proc. ASCE, August 1953.

11. P. Sahmel, Konstruktive Ausbildung und Näherungsbenechaung geschewisster Biegeträger und Torsionsst äbe mit grossen stegausnehmungen [The design, construction and approximate analysis of weld beams and torsion members having large web openings]. Schweissen und Schneiden 213 (1969), pp. 116122.

12. P.W. Chan and R.G. Redwood, Stresses in beams with circular eccentric web holes. J Struct Div Proc. ASCE, 100 ST1 (1974), pp. 231-248.

13. R.G. Redwood, The strength of steel beams with unreinforced web holes. Civil Engng Public Works Rev, London 64755 (1969), pp. 559-562.

14. R. Nayaranan and N.G.V. Der Avanessian, Analysis of plate girders with perforated webs. Thin-Wall Struct 4 (1986), pp. 363-380.

15. S.P. Timoshenko and J.M. Gere (Int. Student edn, 2nd ed.), Theory of elastic stability vol. 541, McGraw-Hill (1985).

16. S.C. Lee, J.S. Davidson and C.H. Yoo, Shear buckling coefficients of plate girder web panels, Computers and Structures 59 (5) (1996), pp. 789-795.

17. S.C. Lee and C.H. Yoo, Strength of plate girder web panels under pure shear, Journal of Structural Engineering ASCE 124 (2) (1998), pp. 184-194.

18. T.C.H. Liu, M.K. Fahad and J.M. Davies, "Experimental investigation of behaviour of axially restrained steel beams in fire". J Construct Steel Res 58 (2002), pp. 1211-1230.

19. V.Vimonsatit, K. H. Tan, S. K. Ting "Shear strength of plate girder web panel at elevated temperature" J Constructional Steel Res 63 (2007), pp. 1442-1451.

20. V.Vimonsatit, K. H. Tan, Z. H. Qian "Testing of plate girder web panel loaded in shear at elevated temperature" ASCE Journal 2007; pp 815-824. 


\section{مقاومة القص للكمرات اللوحيه ذات القتحات بالاعصاب عند درجات الحراره العاليه}

من متطلبات البناء الحديث الوصول الى اقصى عدد من الادوار بالمنشأ وذلك بتقليل ارتفاع الدور .

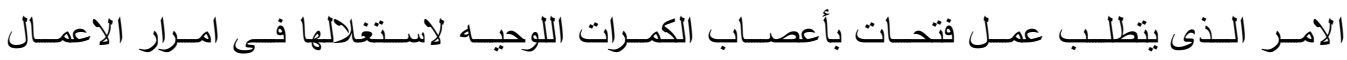
الكهروميكانيكيه اللازمه بالمنشأ. وطرق التصميم الحاليه تتعامل مع الكمرات اللوحيه عند درجات الحراره العاديه (المحيطه) بدون الاخذ

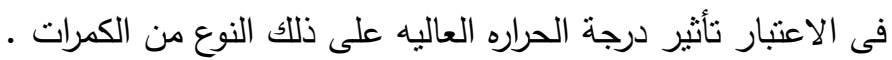

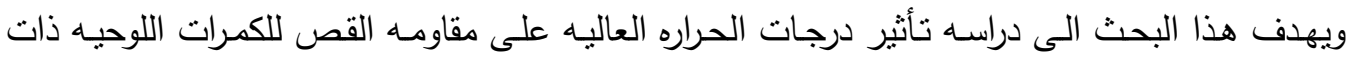
الفتحات مختلفة المساحه المربعه والدائريه الثكل. حيث تم استخدام طريقه العناصر المحدده فى تلك الدراسه وتبين من تلك الدراسه مقدار التأثير الكبير فى مقاومة القص للكمرات اللوحيه نتيجه ارتفاع درجات الحراره. حيث تم الوصول الى معادله لكل حاله من الفتحات سواء مستطيله او مربعه او دائريه لكى تعطى مقدار الانخفاض المتوقع فى مقاومه الكمره للقص المناظر لحجم وشكل كل فتحه بالعصب . 